\title{
Preparation of glass-nickel microcomposites by in situ reduction via sol-gel route
}

\author{
G C DAS*, A BASUMALLICK and S MUKHERJEE \\ Department of Metallurgical Engineering, Jadavpur University, Calcutta 700032, India \\ MS received 25 October 1989; revised 21 May 1990

\begin{abstract}
Gel has been prepared with nickel chloride and glucose in the starting solution followed by heat treatment at higher temperature, where glucose decomposes to carbon and water vapour, which in turn react to form hydrogen in situ to reduce nickel chloride to metallic nickel. The presence and distribution of nickel granules in the microcomposite, has been established by transmission electron microscopy, selected area diffraction and electron paramagnetic resonance analysis.
\end{abstract}

Keywords. In situ reduction; glass nickel microcomposites; sol-gel.

\section{Introduction}

Glass metal microcomposites possess interesting optical (Chakravorty et al 1975; Granqvist and Hunderi 1977; Das et al 1983), electrical (Chakravorty et al 1977; Das et al 1978; Das and Chakravorty 1980) and magnetic properties (Dutta et al 1984) which are functions of shape, size, distribution and the amounts of metallic microgranules present. By conventional methods, only a limited number of metallic species in small amounts can be precipitated in glass (Chakravorty et al 1977; Das and Chakravorty 1980). The preparation of glass-metal micro-composites through sol-gel techniques is rather rare (Carturan et al 1982; Roy and Roy 1984). Hence the preparation of glass-nickel micro-composite through the sol-gel route by in situ reduction has been attempted. The results of this investigation are reported in this work.

\section{Experimental}

Table 1 gives the batch compositions which have been investigated. Required amounts of nickel chloride and glucose are weighed and dissolved completely in $6.5 \mathrm{ml}$ distilled water. To this solution $10 \mathrm{ml}$ of dehydrated ethyl alcohol is added and a homogeneous solution is prepared. $10 \mathrm{ml}$ of ethyl alcohol are then added to $5 \mathrm{ml}$ of TEOS to make a homogeneous solution. The first solution is then added dropwise to the latter with constant stirring. One or two drops of concentrated $\mathrm{HCl}$ is added for adjusting the $\mathrm{pH}$ of the solution in the range 1.8 to $2 \cdot 2$. The solution comprising TEOS, ethyl alcohol, water, nickel chloride and glucose is then heated over a heating mantle at about $60^{\circ} \mathrm{C}$ for 16 to 18 hours for the formation of a gel. Hydrated nickel chloride and glucose are present in the pores of the dried gel. The dried gel (sample 1) is introduced in a tubular furnace at a temperature of $950^{\circ} \mathrm{C}$ in a carbon monoxide

\footnotetext{
*For correspondence.
} 
Table 1. Batch composition of glass-nickel microcomposites.

\begin{tabular}{lccccc}
\hline Sample & $\begin{array}{c}\text { TEOS } \\
(\mathrm{ml})\end{array}$ & $\begin{array}{c}\text { Water } \\
(\mathrm{ml})\end{array}$ & $\begin{array}{c}\text { Dehydrated } \\
\text { ethyl alcohol } \\
(\mathrm{ml})\end{array}$ & $\begin{array}{c}\text { Nickel } \\
\text { chloride } \\
(\mathrm{g})\end{array}$ & $\begin{array}{c}\text { Glucose } \\
(\mathrm{g})\end{array}$ \\
\hline 1 & 5.0 & 6.5 & 20.0 & 0.1520 & 0.0369 \\
2 & 5.0 & 6.5 & 20.0 & 0.3040 & 0.0738 \\
\hline
\end{tabular}

atmosphere for a period of one hour. The carbon monoxide atmosphere is obtained by using activated charcoal in the tubular furnace for the generation of an excessive reducing atmosphere to prevent the subsequent oxidation of $\mathrm{Ni}$. The dried gel (sample 2) is inserted into the tubular furnace maintained at $950^{\circ} \mathrm{C}$ for a period of one hour in a nitrogen atmosphere.

\section{Results and discussion}

The electron paramagnetic resonance (EPR) spectra of 350 mesh heat-treated powdered samples were recorded with a Varian model E109 spectrometer at room temperature $(298 \mathrm{~K})$ using $x$ band cavity and $100 \mathrm{kHz}$ modulation frequency. The magnetic field is standardised with DPPH. Figure 1 shows the EPR spectra for samples 1 and 2. The field set and scan range for samples 1 and 2 are 3390 gauss, 2 kilogauss, and 3990 gauss and 4 kilogauss, respectively. The microstructure of two samples is studied by transmission electron microscopy (JEM-200 $\times$ JEOL). The typical microstructure and the corresponding selected area diffraction (SAD) pattern

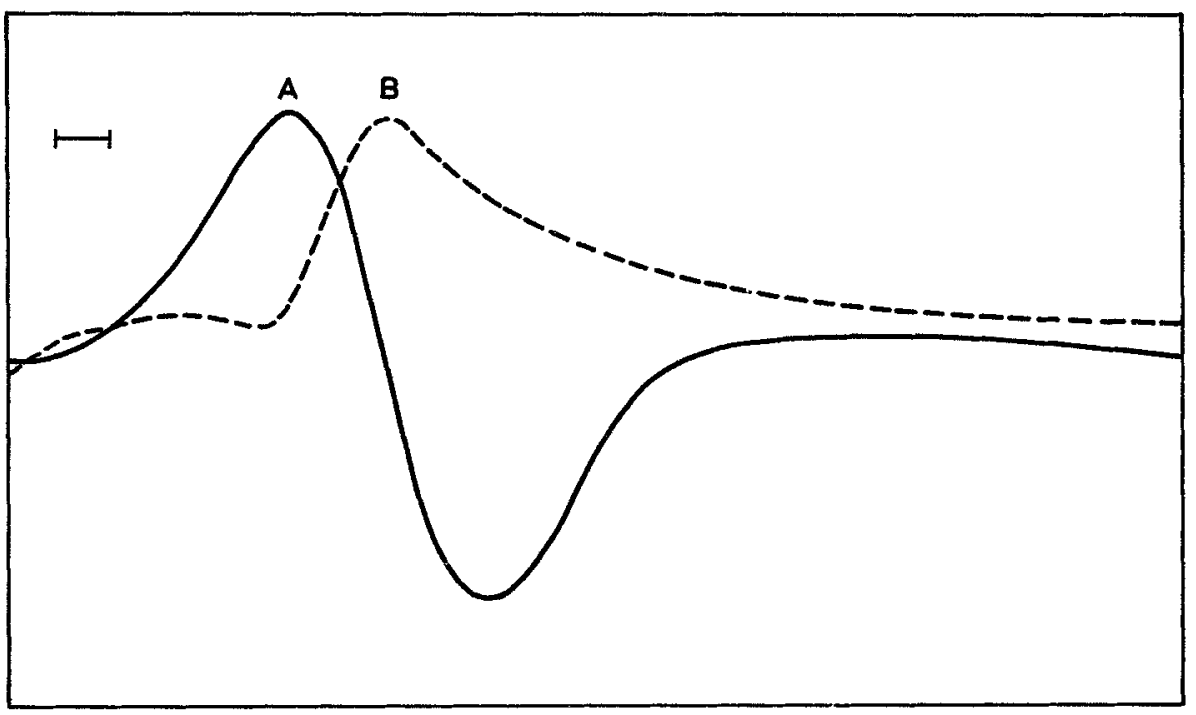

Figure 1. EPR spectra, (A) for sample 1 reduced at $950^{\circ} \mathrm{C}$ for 1 hour in a $\mathrm{CO}$ atmosphere, and (B) for sample 2 reduced at $950^{\circ} \mathrm{C}$ for 1 hour in an $\mathrm{N}_{2}$ atmosphere. Bar indicates $100 \mathrm{G}$ and $200 \mathrm{G}$ for $\mathrm{A}$ and $\mathrm{B}$ respectively. 

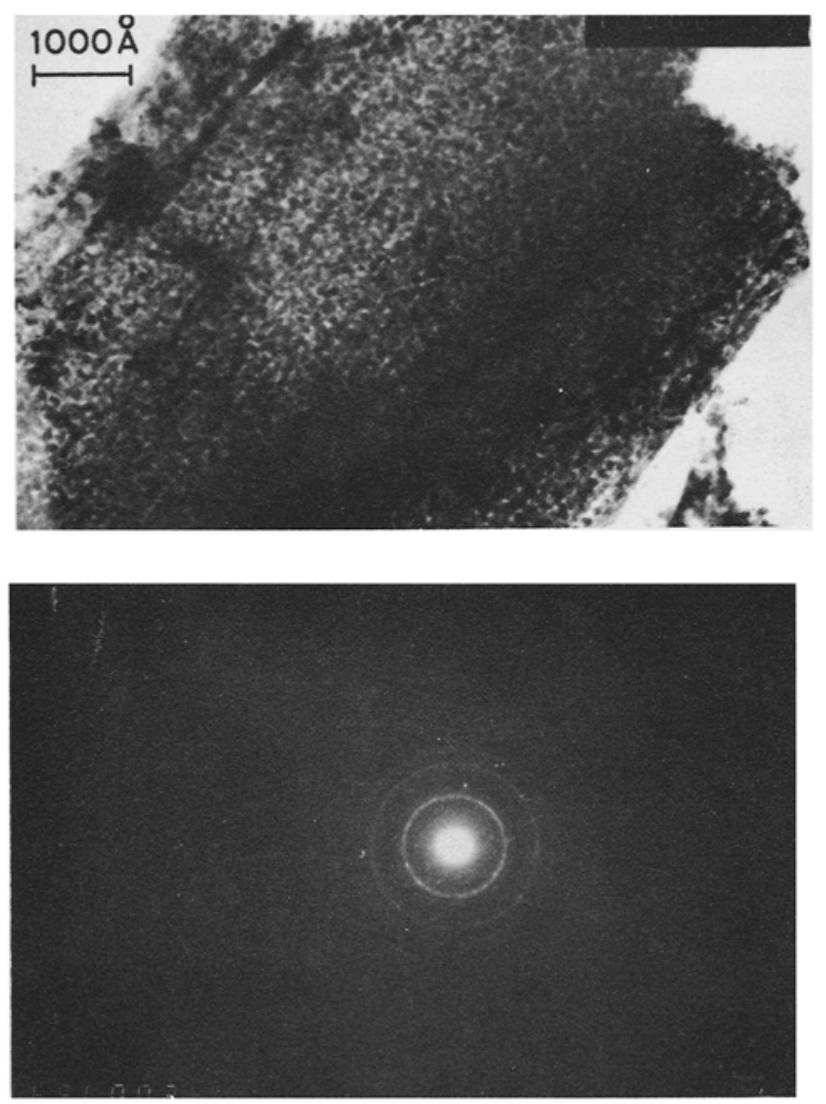

Figure 2. (a) Electron micrograph of sample 1. (b) Selected area diffraction pattern of sample 1 .

for sample 1 are shown in figures $2 a$ and $2 b$ respectively. From the EPR spectra, the computed $g$ values for samples 1 and 2 are $2 \cdot 224$ and $2 \cdot 20$, respectively. These indicate the presence of metallic nickel (Che et al 1980). The radii of the diffraction rings have been measured from the photographic negative of figure $2 b$ to compute the interplanar spacings, $d_{k k l}$. Table 2 contains the computed interplanar spacings $d_{k k l}$ and the standard $d_{h k l}$ values for nickel (Powder Diffraction File 1967). The computed $d_{h k l}$ values match reasonably well with those of standard values and hence metallic nickel is present in the composite. The average size of nickel granules as computed from the micrograph (figure $2 a$ ) is $75 \AA$ while that for sample 2 is $104 \AA$. The metallic nickel in the micro-composites has been estimated by using an atomic absorption spectrophotometer (Perkin-Elmer Model No. 2380). The $\mathrm{Ni} / \mathrm{SiO}_{2}$ ratios of samples 1 and 2 are 0.013 and 0.004 , respectively.

We propose the following mechanism of reduction. At high temperature glucose breaks up giving rise to activated carbon and water vapour at about $280^{\circ} \mathrm{C}$.

The activated carbon reacts with water vapour obtained from the glucose and from the gel to form hydrogen by the following reactions,

$$
\mathrm{C}_{6} \mathrm{H}_{12} \mathrm{O}_{6}=6 \mathrm{C}+6 \mathrm{H}_{2} \mathrm{O} \text {, }
$$


Table 2. Comparison of $d_{h k l}$ values $(\AA)$ as computed from SAD pattern of sample 1 with standard values for nickel.

\begin{tabular}{lc}
\hline $\begin{array}{l}\text { Computed } \\
\text { values }\end{array}$ & $\begin{array}{c}\text { Standard } \\
\text { values }\end{array}$ \\
\hline 1.540 & - \\
1.253 & 1.246 \\
1.050 & 1.062 \\
0.898 & 0.881 \\
0.773 & 0.788 \\
0.560 & - \\
0.516 & - \\
\hline
\end{tabular}

$$
\mathrm{C}+\mathrm{H}_{2} \mathrm{O}=\mathrm{CO}+\mathrm{H}_{2} \text {. }
$$

The hydrogen so generated reduces nickel chloride which is present in the pores of the gel by the reaction,

$$
\mathrm{H}_{2}+\mathrm{NiCl}_{2}=\mathrm{Ni}^{\circ}+2 \mathrm{HCl} \text {. }
$$

Thus hydrogen is generated in situ to reduce the nickel chloride to form glassnickel microcomposites through the sol-gel route.

\section{Acknowledgements}

We thank Mr S Ghosh for helping in the photographic work.

\section{References}

Carturan G, Facchin G, Gottardi V, Gulielmi M and Navazio G 1982 J. Non-Cryst. Solids 48219

Chakravorty D, Bandopadhyay A K and Nagesh V K 1977 J. Phys. D, Appl. Phys. 102077

Chakravorty D, Shuttleworth A and Gaskell P H 1975 J. Mater. Sci. 10799

Che M, Richard M and Olivier D $1980 \mathrm{~J}$. Chem. Soc., Faraday I 761526

Das G C and Chakravorty D 1980 J. Appl. Phys. 513896

Das G C, Das R and Chakravorty D 1983 Bull. Mater. Sci. 5277

Das G C, Reddy T K and Chakravorty D 1978 J. Mater. Sci. 132211

Dutta S, Bahadur D and Chakravorty D 1984 J. Phys. D, Appl. Phys. 17163

Granquist C G and Hunderi O 1977 Phys. Rev. B16 3513

Powder Diffraction File 1967 (Revised) Published by the Joint Committee on Powder Diffraction Standards, Philadelphia, Pennsylvania

Roy R A and Roy R 1984 Mater. Res. Bull. 19169 